\title{
Pengerasan Permukaan Pisau Hammer Mill AISI 1022 dengan Metode Nitridasi dalam Larutan Campuran Kalium Nitrat dan Sodium Nitrit
}

\author{
*Yusuf Umardani, Rigo Muhammad Herriza \\ Departemen Teknik Mesin, Fakultas Teknik, Universitas Diponegoro \\ Jl. Prof. Soedarto, SH, Kampus Undip Tembalang, Semarang, Indonesia 50275 \\ *E-mail: umardaniyusuf70@gmail.com
}

\begin{abstract}
Hammer mill machines require a hammer mill blade that has a hard surface and wear resistance with a minimum hardness value of 55-60HRC or equivalent to 600-700HV. Based on the results of the hardness test on PT. Charoen Pokphand Indonesia Semarang branch office, obtained the value of blade surface hardness of 727 HV. Basic materials for making hammer mill blades use high carbon steel which is relatively expensive and difficult to machining. In this research, hammer mill blades are made with low carbon steel which is relatively inexpensive and easy to machining with surface hardening treatment so that the hardness value can match hammer mill blades made of high carbon steel. In this research, the surface hardening used on hammer mill blades that made of AISI 1022 steel. The method used is liquid nitriding. The parameters used as variation is holding time in nitriding. Nitriding was carried out using a KNO3+NaNO2 with a ratio of 50:50 at a temperature of $310^{\circ} \mathrm{C}$. The steps of nitriding testing begin with liquefying KNO3 with NaNO2 in the nitriding vessel, heating specimens in the furnace to austenite to accelerate the diffusion process, and then the material is quenched into a salt bath with 3 variations of holding time, 4 hours, 8 hours, 12 hours. From these tests it is known that the nitriding method can increase the value of material hardness from $213.3 \mathrm{HV}$ to $627 \mathrm{HV}$. Micrography testing revealed that the formation of a nitrid layer with a thickness of $554 \mu \mathrm{m}$ in a holding time of 4 hours, $704 \mu \mathrm{m}$ in an 8 hour holding time, and $977 \mu \mathrm{m}$ at 12 hours of holding time. These results indicate that the holding time is directly proportional to the diffusion rate and the hardness value and nitrid layer can still increase with the length of time of detention.
\end{abstract}

Keywords: nitriding, surface hardening, hammer mill blade.

\begin{abstract}
Abstrak
Mesin hammer mill memerlukan pisau hammer mill yang memiliki permukaan keras dan tahan aus dengan minimal nilai kekerasannya 55-60 HRC atau setara dengan 600-700 HV [8]. Dari hasil uji kekerasan pada pisau hammer mill PT. Charoen Pokphand Indonesia cabang Semarang diperoleh nilai kekerasan permukaan pisau sebesar $727 \mathrm{HV}$. Material dasar untuk membuat pisau hammer mill menggunakan baja karbon tinggi yang relatif mahal dan sulit untuk dilakukan machining. Dalam penelitian ini pisau hammer mill dibuat dengan baja karbon rendah yang relatif murah dan mudah dalam machining dengan diberikan perlakuan pengerasan permukaan agar nilai kekerasan bisa menyamai pisau hammer mill yang dibuat dari baja karbon tinggi. Baja karbon rendah yang digunakan merupakan baja AISI 1022. Metode yang digunakan adalah metode nitridasi cair. Parameter yang digunakan sebagai variasi waktu penahanan. Nitridasi dilakukan menggunakan larutan garam $\mathrm{KNO}_{3}+$ $\mathrm{NaNO}_{2}$ dengan perbandingan 50:50 di temperatur $310^{\circ} \mathrm{C}$. Langkah - langkah pengujian nitridasi diawali dengan mencairkan $\mathrm{KNO}_{3}$ dengan $\mathrm{NaNO}_{2}$ pada bejana nitridasi, memanaskan spesimen didalam furnace hingga austenite guna membantu dan mempercepat proses difusi, dan material tersebut di quenching kedalam larutan garam dengan 3 variasi waktu penahanan yaitu 4 jam, 8 jam, 12 jam. Dari pengujian tersebut diketahui bahwa metode nitridasi mampu menaikan nilai kekerasan material dari semula 213,3 HV menjadi 627 HV. Dari pengujian mikrografi diketahui bahwa terbentuknya lapisan nitrid dengan ketebalan $554 \mu \mathrm{m}$ di waktu penahanan 4 jam, $704 \mu \mathrm{m}$ di waktu penahanan 8 jam, dan $977 \mu \mathrm{m}$ di waktu penahanan 12 jam. Hasil tersebut menunjukan bahwa waktu penahanan berbanding lurus dengan laju difusi dan nilai kekerasan serta lapisan nitrid masih dapat meningkat seiring dengan lamanya waktu penahanan
\end{abstract}

Kata kunci: nitridasi, kekerasan permukaan, pisau hammer mill.

\section{Pendahuluan}

Industri pakan ternak di Indonesia terus bertumbuh $10 \%$ dari tahun 2014. Hal tersebut diakibatkan meningkatnya konsumsi pakan hingga mencapai 14,7 juta ton dan akan terus meningkat [1]. Industri pakan ternak pakan ternak umumnya menggunakan mesin hammer mill untuk mengolah bahan baku pakan ternak yang bentuk dan ukuran 
bermacam-macam menjadi pakan ternak siap kemas dengan ukuran yang sudah seragam. Mesin ini mempunyai suatu bagian yang berfungsi sebagai penghancur bahan baku tersebut, yaitu pisau hammer mill. Pisau ini bergesekan langsung dengan bahan baku yang menyebabkan sering terjadinya keausan. Pisau hammer mill umumnya dibuat dengan baja karbon tinggi yang relatif mahal khususnya bagi industri penyedia pakan ternak berskala kecil. Tujuan penelitian ini adalah mengidentifikasi dan merekayasa nilai kekerasan permukaan pisau hammer mill dengan material dasar baja karbon rendah yang mudah diperoleh dipasaran dan relatif lebih murah agar dapat bersaing dengan pisau hammer mill yang berbahan dasar baja karbon tinggi . Untuk mendapat pisau hammer mill yang tidak mudah aus, keras, dan ulet dari baja karbon rendah, perlu dilakukan peningkatan kualitas baja khususnya dibagian permukaannya. Dalam bidang rekayasa material, teknik pengerasan permukaan sering dikenal dengan istilah "perlakuan permukaan" (surface treatment) [5].

Salah satu penelitian mengenai nitridasi dengan variasi waktu penahanan pernah dilakukan oleh Muhamad khoirul Amin, Universitas Diponegoro Semarang. Pada penelitian tersebut, material yang digunakan adalah baja karbon rendah dengan variasi waktu penahanan $1 \mathrm{jam}, 2$ jam, dan 3 jam pada temperatur $550^{\circ} \mathrm{C}$ dan diperoleh hasil kekerasan dan tebal lapisan nitrid yang terbentuk berbanding lurus dengan waktu penahanan [6]. Pada penelitian tersebut diketahui bahwa faktor utama yang mempengaruhi peningkatan nilai kekerasan pada metode nitridasi adalah temperatur nitridasi dan waktu penahanannya. Pada penelitian ini, analisa dilakukan untuk mengetahui peningkatan nilai kekerasan dan perubahan struktur mikro yang terjadi akibat nitridasi cair pada variasi waktu penahanan 4 jam, 8 jam, dan 12 jam.

\section{Material dan metode penelitian}

Pada Gambar 1 merupakan diagram alir penelitian nitridasi dengan menggunakan campuran kalium nitrat dan sodium nitrit yang memberikan efek pada nilai kekerasan permukaan dan struktur mikro baja AISI 1022. Penelitian dilakukan di Laboratorium Metalurgi Fisis Teknik Mesin Undip.

Studi literatur dilakukan untuk mencari teori dan materi yang berhubungan dengan penelitian yang dilakukan dan Pemilihan material dilakukan untuk menentukan jenis material yang akan digunakan dalam penelitian. Pengujian komposisi kimia dilakukan di Laboratorium Logam Bahan PT Itokoh Ceperindo, Klaten dengan menggunakan Spektrometer. Pengujian ini bertujuan untuk mengetahui komposisi kimia yang terkandung dalam spesimen hammer mill. Hasil pengujian komposisi spesimen hammer mill dapat dilihat pada Tabel 1. Berdasarkan Tabel 1 dapat diketahui material spesimen hammer mill memiliki kandungan Fe sebesar 97,52\% dan kandungan $\mathrm{C}$ sebesar 0,2307\%. Dengan diketahuinya kedua unsur tersebut, maka dapat diklasifikasikan sebagai baja karbon rendah karena memiliki kadar karbon dibawah 0,25\% [2]. Dengan terdapatnya unsur C, Mn, P, Si, Ni, Cr dan Mo maka material hammer mill dapat diklasifikasikan sebagai baja AISI 1022.

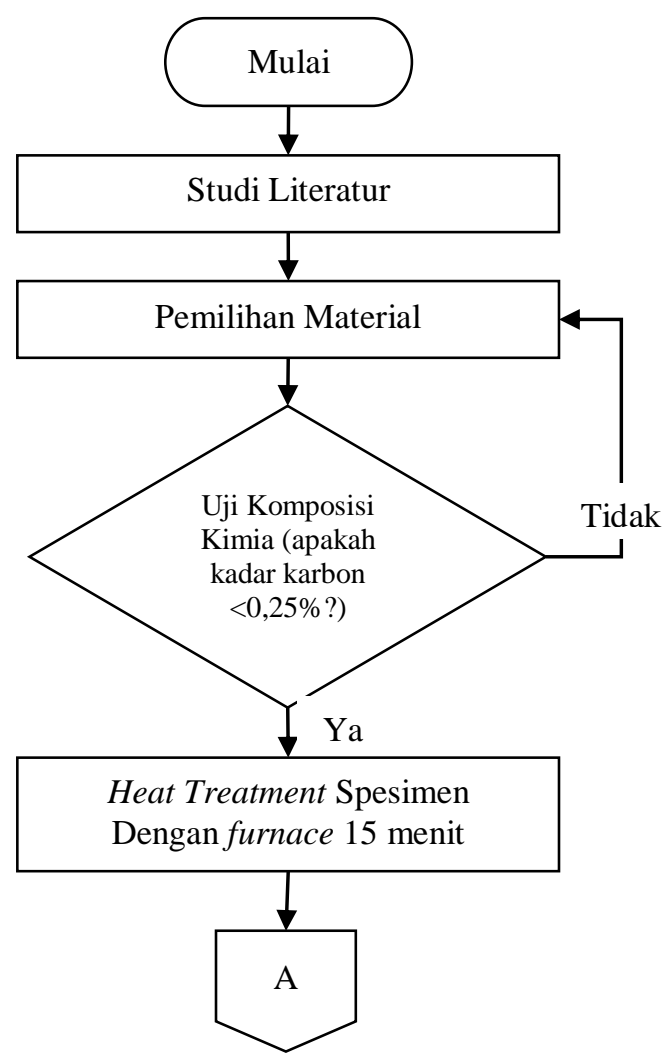

Gambar 1. Diagram Alir Metode Penelitian 


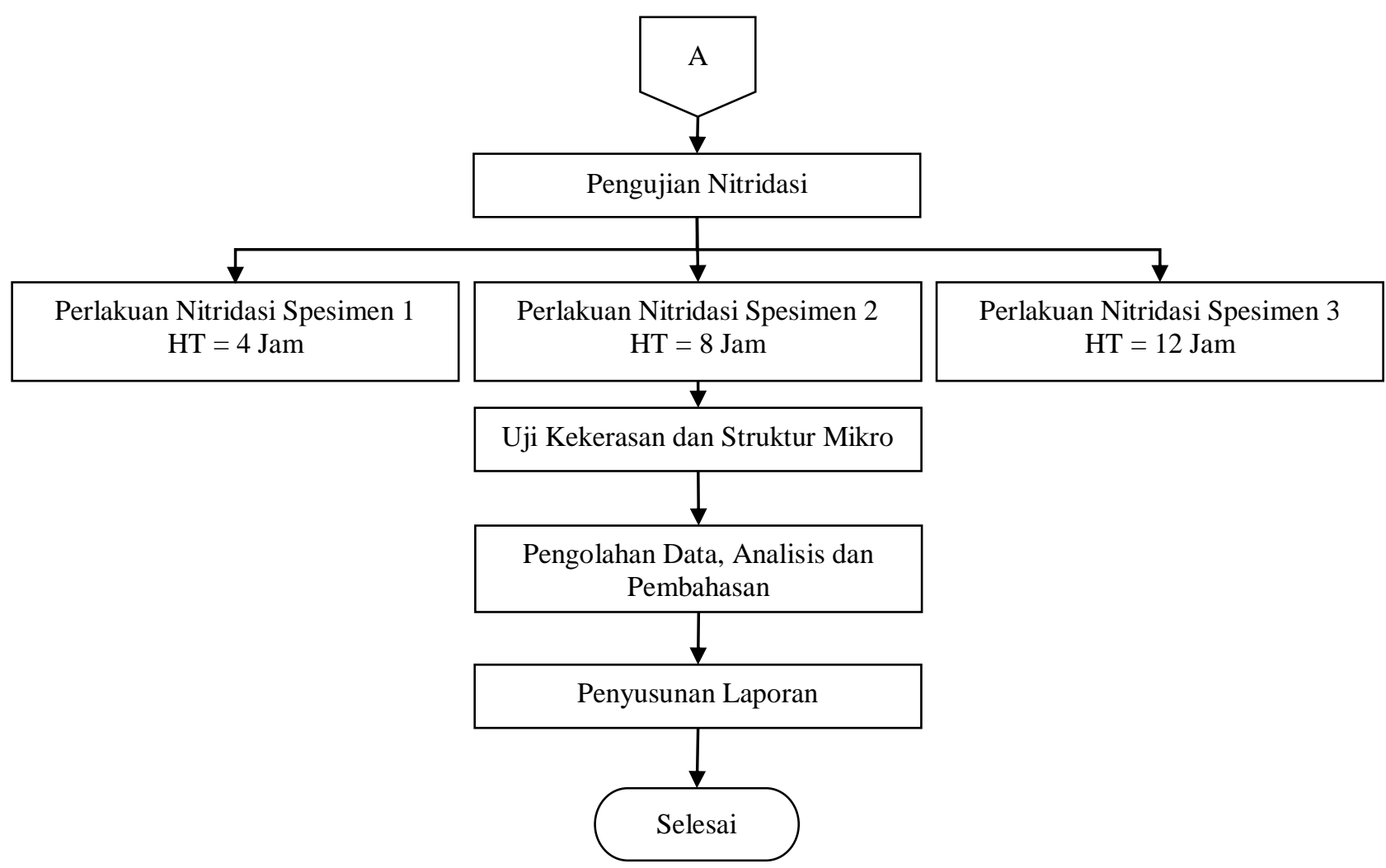

Gambar 1. Diagram Alir Metode Penelitian (Lanjutan)

Tabel 1. komposisi kimia pada material hammer mill

\begin{tabular}{|c|c|c|c|c|c|c|c|c|c|c|c|c|c|c|c|}
\hline nsur & $\mathrm{Fe}$ & $\mathrm{C}$ & $\mathrm{Si}$ & $\mathrm{Mn}$ & $\mathrm{Cr}$ & $\mathrm{P}$ & Mo & $\mathrm{Ni}$ & $\mathrm{Al}$ & Co & $\mathrm{Cu}$ & $\mathrm{Nb}$ & $\mathrm{Ti}$ & $\mathrm{V}$ & W \\
\hline ersentase & 97,52 & 0,2307 & 0,901 & 0,928 & 0,080 & $<0,1$ & 0,004 & 0,026 & $<0,005$ & 0,005 & 0,132 & 0,0019 & 0,0017 & $<0,1$ & $<0,1$ \\
\hline
\end{tabular}

Pada penelitian ini dilakukan nitridasi menggunakan $\mathrm{KNO}_{3}+\mathrm{NaNO}_{2}$ pada temperatur $310^{\circ} \mathrm{C}$ dengan variasi waktu penahanan 4 jam, 8 jam, dan 12 jam. Kemudian dilakukan uji keras dan mikrografi untuk mengetahui pengaruh nitridasi terhadap kekerasan permukaan dan struktur mikro material pisau hammer mill.

\section{Hasil dan pembahasan}

\subsection{Hasil pengujian kekerasan}

Dari hasil sebelum (raw material) dan sesudah pengerasan permukaan menggunakan metode nitridasi dilakukan pengujian kekerasan menggunakan alat uji mikro hardness Vickers HM-200 Mitutoyo di laboratorium terpadu UNDIP dengan melakukan pembebanan sebesar $0,3 \mathrm{kgf}$ terhadap spesimen hammer mill. Gambar 2 menunjukkan titik penyebaran pengujian kekerasan dimana setiap titik uji berada $1 \mathrm{~mm}$ dari tepi. Hasil nilai kekerasan permukaan ditunjukkan pada Tabel 2.

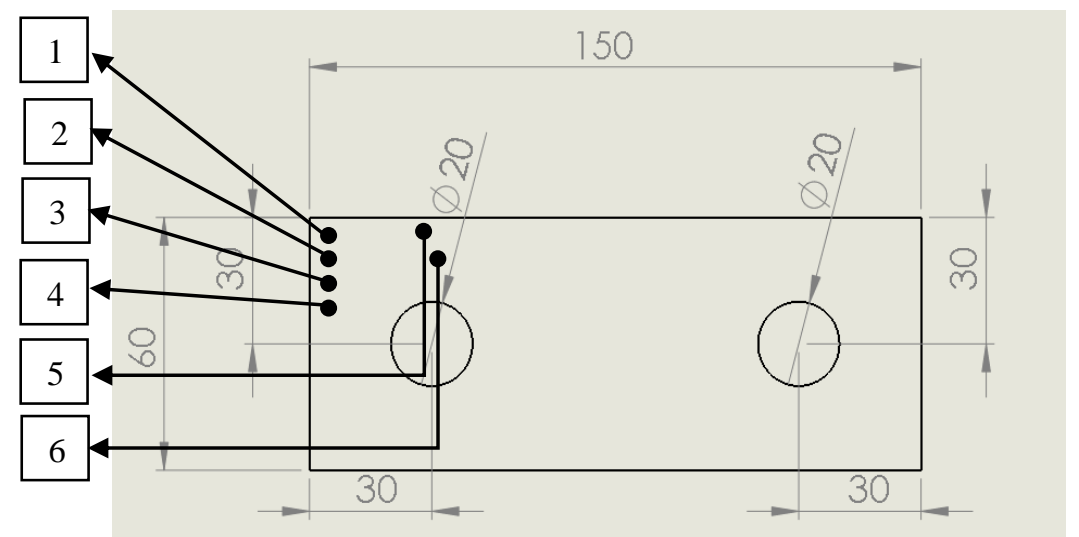

Gambar 2. Dimensi dan persebaran titik pengujian kekerasan di permukaan pisau hammer mill 
Tabel 2. Hasil pengujian kekerasan permukaaan spesimen hammer mill

\begin{tabular}{cccccc}
\hline No & Kekerasan permukaan $(\mathbf{H V})$ & Spesimen sebelum hardening & Nitridasi 4 jam & Nitridasi 8 jam & Nitridasi 12 jam \\
\hline $\mathbf{1}$ & Titik 1 & 213,4 & 529,0 & 552,2 & 627,0 \\
$\mathbf{2}$ & Titik 2 & 204,8 & 516,7 & 546,5 & 579,4 \\
$\mathbf{3}$ & Titik 3 & 223,9 & 502,0 & 508,6 & 563,1 \\
$\mathbf{4}$ & Titik 4 & 212,3 & 493,8 & 521,4 & 541,3 \\
$\mathbf{5}$ & Titik 5 & 218,7 & 497,8 & 492,0 & 533,7 \\
$\mathbf{6}$ & Titik 6 & 218,0 & 475,3 & 477,0 & 503,0 \\
\hline
\end{tabular}

Dari hasil pengujian kekerasan pada spesimen uji diketahui bahwa perlakuan pengerasan dengan menggunakan metode nitridasi dapat meningkatkan nilai kekerasan baja AISI 1022 yang merupakan baja karbon rendah. Pada Gambar 3 terlihat bahwa kekerasan paling tinggi pada baja yang telah mengalami proses nitridasi di masing-masing spesimen terdapat pada titik satu yaitu titik yang terletak pada bagian tepi ujung spesimen yakni pada 4 jam nitridasi $=529,0 \mathrm{HV}$, 8 jam nitridasi $=552,2 \mathrm{HV}$, dan 12 jam nitridasi 627,0 HV. Hal ini terjadi karena pada daerah yang dekat dengan sisisisi permukaan, konsentrasi atom-atom nitrogen yang terdifusi kedalam atom baja akan jauh lebih besar bila dibandingkan dengan daerah pada pusat permukaan. Dengan turunnya konsentrasi atom nitrogen yang terdifusi secara intersiti kedalam atom-atom baja, maka dengan sendirinya akan menurunkan nilai kekerasan pada permukaan pada baja.

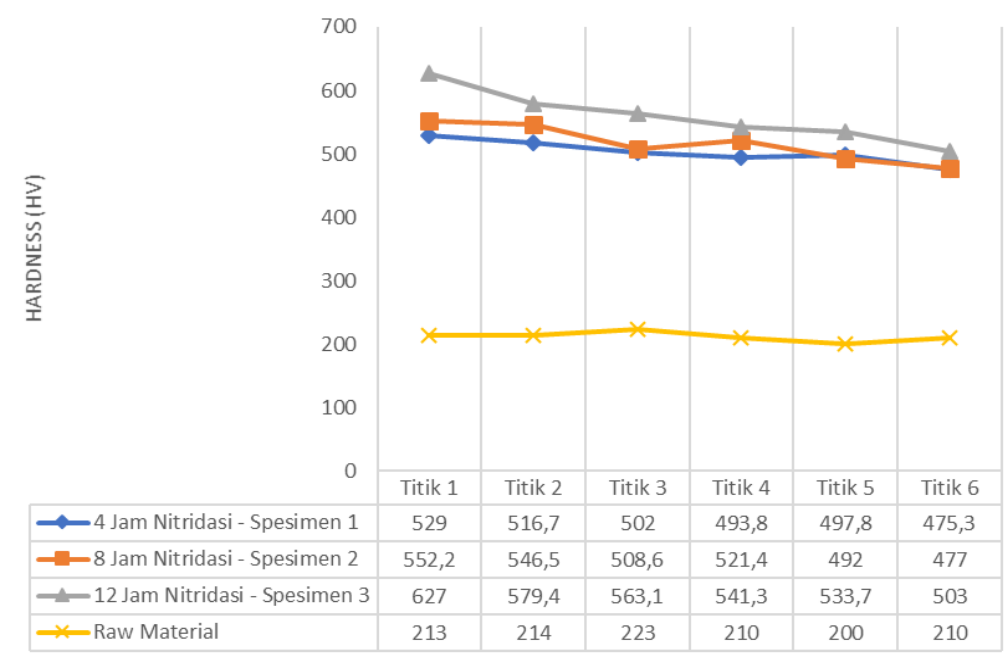

Gambar 3. Grafik Analisis kekerasan sebelum dan setelah hardening bagian permukaan

\subsection{Hasil pengujian mikrografi}

Pengujian mikrografi dilakuan untuk mengetahui struktur mikro dari spesimen pisau hammer mill sebelum dan setelah mengalami perlakuan plasma, sehingga dapat diketahui perubahan struktur mikro yang terjadi. Pengujian mikrografi menggunakan mikroskop optik yang dilengkapi dengan optilab untuk mengambil gambar dengan resolusi tertentu. Pengujian mikrografi ini dilakukan di Laboratorium Metalurgi Fisik Departemen Teknik Mesin Universitas Diponegoro. Pengambilan gambar struktur mikro spesimen awal dilakukan bertujuan untuk sebagai pembanding ada tidaknya perubahan yang terjadi sebelum dan sesudah proses perlakuan menggunakan plasma. Gambar 4 ini menunjukkan struktur mikro dari material awal yaitu baja AISI 1022 yang merupakan baja karbon rendah dan didominasi struktur ferit (putih) dibandingkan dengan perlit (hitam).

Pengujian struktur mikro pada spesimen yang telah melalui proses nitridasi dilakukan untuk mengetahui pengaruh waktu penahanan terhadap struktur mikro specimen [7]. Gambar 4 diatas merupakan perbandingan antara permukaan spesimen tanpa perlakuan dengan yang mengalami perlakuan nitridasi dengan variasi waktu penahanan. Pertumbuhan butir perlit ini terbentuk akibat pendifusian unsur nitrogen yang terlarut padat pada permukaan spesimen uji yang menyebabkan tumbuhnya butiran austenit. Butiran austenit yang mengalami proses pendinginan yang lambat akan bertransformasi menjadi butiran perlit, sehingga hal ini dapat membuktikan serta mendukung analisa kenaikan nilai kekerasan pada permukaan spesimen uji. Butiran fasa perlit yang terbentuk memiliki sifat kekerasan yang lebih baik bila dibandingkan dengan fasa ferit, butiran perlit memiliki sifat kekerasan, dan ketangguhan serta ketahanan yang tinggi terhadap faktor korosi. Selain fasa ferit dan perlit, terdapat struktur lain yang terbentuk pada bagian permukaan material. Gambar 5 ini menunjukan perbandingan struktur bainit yang terdapat pada literatur dengan struktur yang diperoleh dari pengujian nitridasi. 


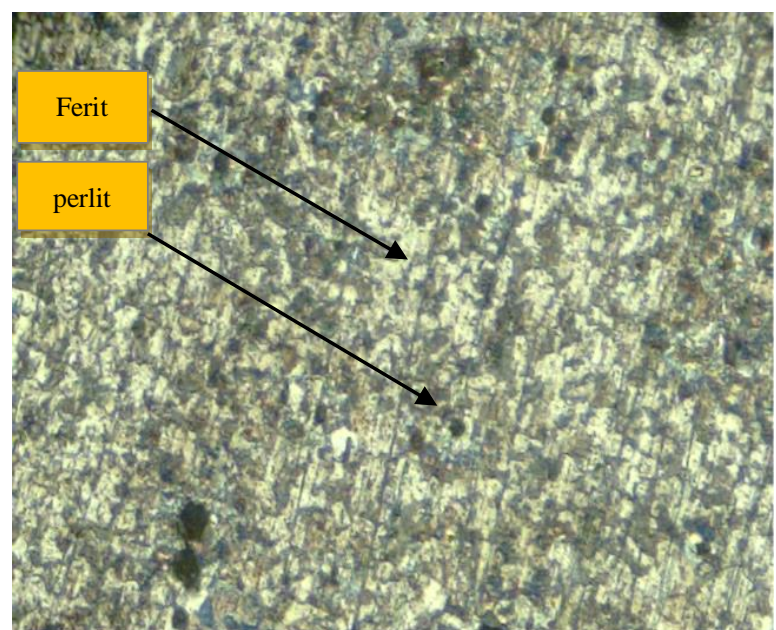

(a)

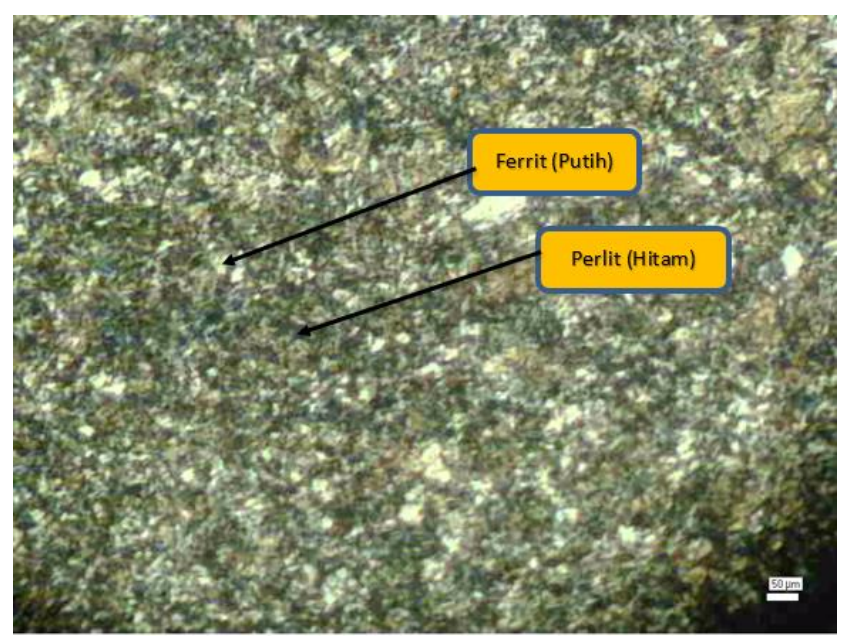

(b)

Gambar 4. Struktur mikro perbesaran 100x. (a) raw material, (b) setelah nitridasi dengan penahanan 12 jam

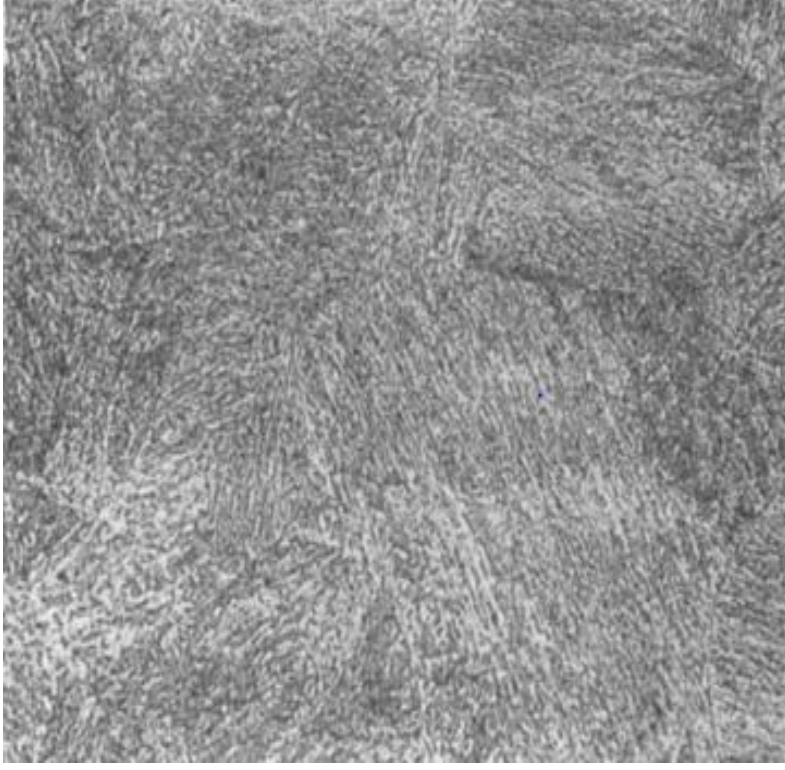

(a)

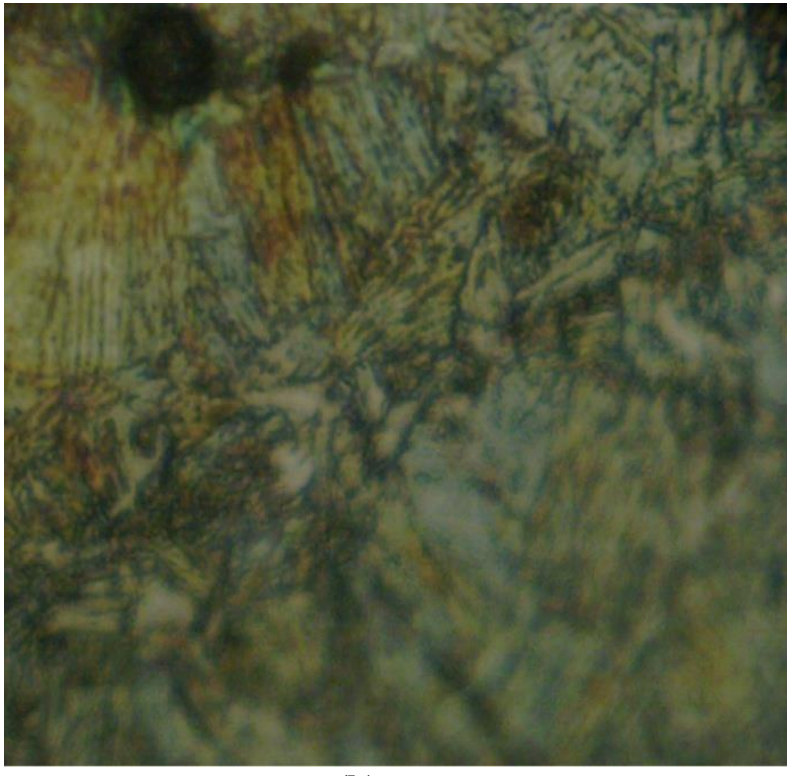

(b)

Gambar 5. Struktur bainit yang terbentuk pada permukaan material (a) lower bainit dari literatur [4] (b) lower bainit dari pengujian nitridasi dengan penahanan 12 jam.

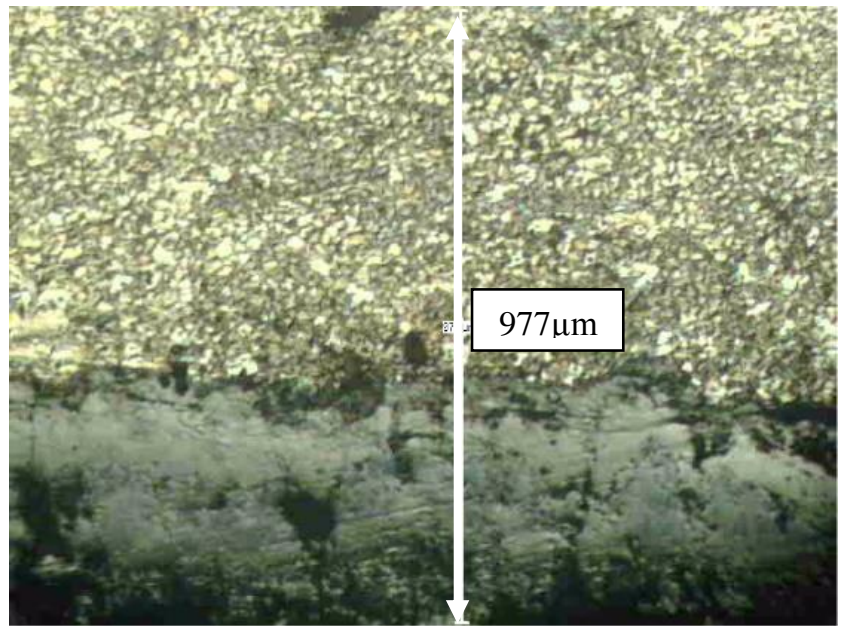

Gambar 6. Ketebalan lapisan nitrida pada spesimen 3 (12 jam nitridasi) 
Pengujian struktur pada mikro penampang melintang spesimen yang telah melalui proses nitridasi dilakukan untuk mengetahui kedalaman pengerasan yang dihasilkan. Berikut ini adalah Gambar 6 ketebalan lapisan nitridasi pada spesimen ketiga 12 jam nitridasi. Pada Gambar 6 terlihat bahwa diffusion layer yang terbentuk pada waktu penahanan 12 jam adalah sebesar $977 \mu \mathrm{m}$. Tebal lapisan tersebut adalah yang paling besar dibandingkan spesimen dengan waktu penahanan 4 jam sebesar $554 \mu \mathrm{m}$, dan 8 jam sebesar $704 \mu \mathrm{m}$.

\section{Kesimpulan}

Dari hasil analisis hasil uji kekerasan dan mikrografi pada pisau hammer mill diketahui bahwa pisau hammer mill mengalami peningkatan kekerasan setelah mengalami pengerasan permukaan dengan menggunakan metode nitridasi. Peningkatan kekerasan yang terjadi berbanding lurus dengan waktu penahanan nitridasi. Nilai kekerasan maksimum yang diperoleh pada masing-masing spesimen yaitu : 4 jam $=529,0 \mathrm{HV}, 8$ jam $=552,2 \mathrm{HV}$, dan 12 jam $=627,0 \mathrm{HV} .3$. Proses nitridasi berpengaruh terhadap perubahan struktur mikro Baja AISI 1022, perubahan ini terlihat berdasarkan hasil foto struktur mikro dengan perbesaran 50x dan 100x dimana terlihat bertambahnya ketebalan lapisan seiring dengan lamanya waktu penahanan nitridasi.

\section{Daftar Pustaka}

[1] Aminata, R.N., Muhaimin, A.W., Primingtyas, D.N., (2015), Analisis Kinerja Pemasok Bahan Baku Utama Pakan Ternak Kasus di Perusahaan Agroindustri Pakan Ternak PT. Japfa Comfeed Indonesia Unit Gendangan, Habitat, vol. 26, hal. 80-88.

[2] ASM, (1993) ASM Handbook Volume 1 Properties and Selection: Irons Steels and High Perfomance Alloys, ASM International, USA

[3] ASM Team, (1991), ASM Handbook Volume 4 Heat Treating, ASM International, USA

[4] ASM, (2004), ASM Handbook Volume 9 Metallography and Microstructures, ASM International, USA

[5] Callister, W. D., Rethwisch, D. G., (2010), Materials Science and Engineering an Introduction Eight Edition, John Wiley \& Sons, Inc, USA.

[6] Amin K., (2014), Pengerasan Permukaan Hammer Mill Menggunakan Metode Nitriding, Laporan tugas akhir, Universitas Diponegoro Semarang.

[7] Benlahreche, F.B., Nouicer, E., (2017), Improvement of Surface Properties of Low Carbon Steel by Nitriding Treatment, Acta physica polonica, vol.131, hal. 20-23.

[8] McEllhiney, R.R., (2005), Feed Manufacturing Tecnology V, Texas: American feed industry association.

[9] Pratama D.D., ( 2011 ), Diffusion in Solid, Makalah Material Teknik, Universitas Sultan Agung Tirtayasa, Cilegon

[10] Shen,Y.Z., Oh, K.H., Lee, D.N., (2005), Nitriding of Steel in Potassium Nitrate salt bath, Seripta materialia, vol.53, hal.1345-1349. 